\title{
Long-term outcomes following a normal stress myocardial perfusion scan
}

\author{
Seth Uretsky, $M D{ }^{a, b}$ and Alan Rozanski, $M D^{a, b}$
}

\section{See related article, pp. 748-754}

Stress-rest single-photon emission computed tomography (SPECT) myocardial perfusion imaging (MPI) has been used for nearly forty years for the diagnostic assessment of patients with suspected coronary artery disease (CAD), and for making important patient management decisions, such as determining who needs cardiac catheterization or myocardial revascularization. Decision-making using SPECT-MPI is based on its proven prognostic efficacy. Principally, a normal SPECTMPI study establishes patients as to who are at low risk of subsequent adverse clinical events, ${ }^{1,2}$ and among patients with inducible myocardial ischemia, clinical risk increases in exponential relationship to the magnitude of inducible myocardial ischemia. ${ }^{3,4}$ These findings have been robustly demonstrated through a serial study.

Recently, however, there has been a growing recognition that the prognostic significance associated with a normal SPECT-MPI study needs to be more closely evaluated. For many years, the nuclear cardiology community promulgated that a normal SPECT-MPI study provides a "warranty" for low risk. Notably, this "warranty", was based on short-term outcome studies, often involving follow-up of only 2-3 years' duration. The danger is that such thinking might lull both physicians and patients into a false sense of security relative to modifying cardiovascular risk factors. Recently, Supariwala et $\mathrm{al}^{5}$ reported that when patients with normal SPECT studies are followed over a longer time span, there is considerable heterogeneity in outcomes among patients with normal exercise SPECT-MPI studies. In

From the Division of Cardiology and Department of Medicine, St. Luke's and Roosevelt Hospitals; and the Department of Medi-

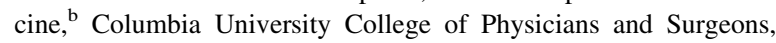
New York, NY

Reprint requests: Seth Uretsky, MD, Division of Cardiology and Department of Medicine, St. Luke's and Roosevelt Hospitals, 1111 Amsterdam Ave, New York, NY 10025; suretsky@chpnet.org.

J Nucl Cardiol 2013;20:715-8.

1071-3581/\$34.00

Copyright (C) 2013 American Society of Nuclear Cardiology.

doi:10.1007/s12350-013-9769-0 particular, the presence of hypertension, smoking, and diabetes were all significant predictors of long-term risk. Annual all-cause mortality rate was $0.2 \%$ among patients with none of these three risk factors, $0.6 \%$ among those with one of these risk factors, $1.3 \%$ with two of these risk factors, and $1.7 \%$ for those with all three of these risk factors. ${ }^{5}$ Additional risk is identified among patients who undergo pharmacological as opposed to exercise SPECT-MPI. ${ }^{6}$ The greater risk associated with pharmacological SPECT-MPI has been thought to be because of the older age and greater frequency of comorbidities in such patients. However, one study-where exercise and adenosine SPECT-MPI patients were propensity matched to have similar riskfactor profiles, and patients with any cardiac morbidities were excluded-showed that patients with normal adenosine SPECT-MPI studies still had greater mortality than normal exercise studies in all age groups (Figure 1). ${ }^{7}$ Subsequent study has demonstrated that when both CAD risk factors and the consideration of exercise vs pharmacological stress testing are all considered, there is a marked variability in long-term outcomes among patients with normal SPECT-MPI studies (Figure 2). ${ }^{8}$

To-date, the studies concerning long-term follow-up with normal SPECT-MPI have largely focused on patients with suspected CAD, with exclusion of patients with known CAD. By contrast, in this issue of the Journal of Nuclear Cardiology, Ottenhoff et al report their findings concerning a 12-year follow up of 266 patients with known CAD and normal SPECT-MPI studies. Known CAD was defined on the basis of a prior myocardial infarction and/or a history of a myocardial revascularization procedure. Within this cohort, the annualized all-cause mortality rate was $3.1 \%$, and the cardiac mortality rate was $0.9 \%$. The annualized event rate for cardiac death and/or non-fatal myocardial infarction was $1.2 \%$. These event rates do not vary significantly from prior studies involving short-term outcomes among patients with known CAD following SPECT-MPI. For example, Hachamovitch et $\mathrm{al}^{9}$ found that among patients with a normal SPECT-MPI, those with known CAD had a significantly higher event rate for cardiac death or non-fatal myocardial infarction than those without known CAD (1.4 vs $0.4 \%$ /year) over a mean 1.8-year follow-up period. 

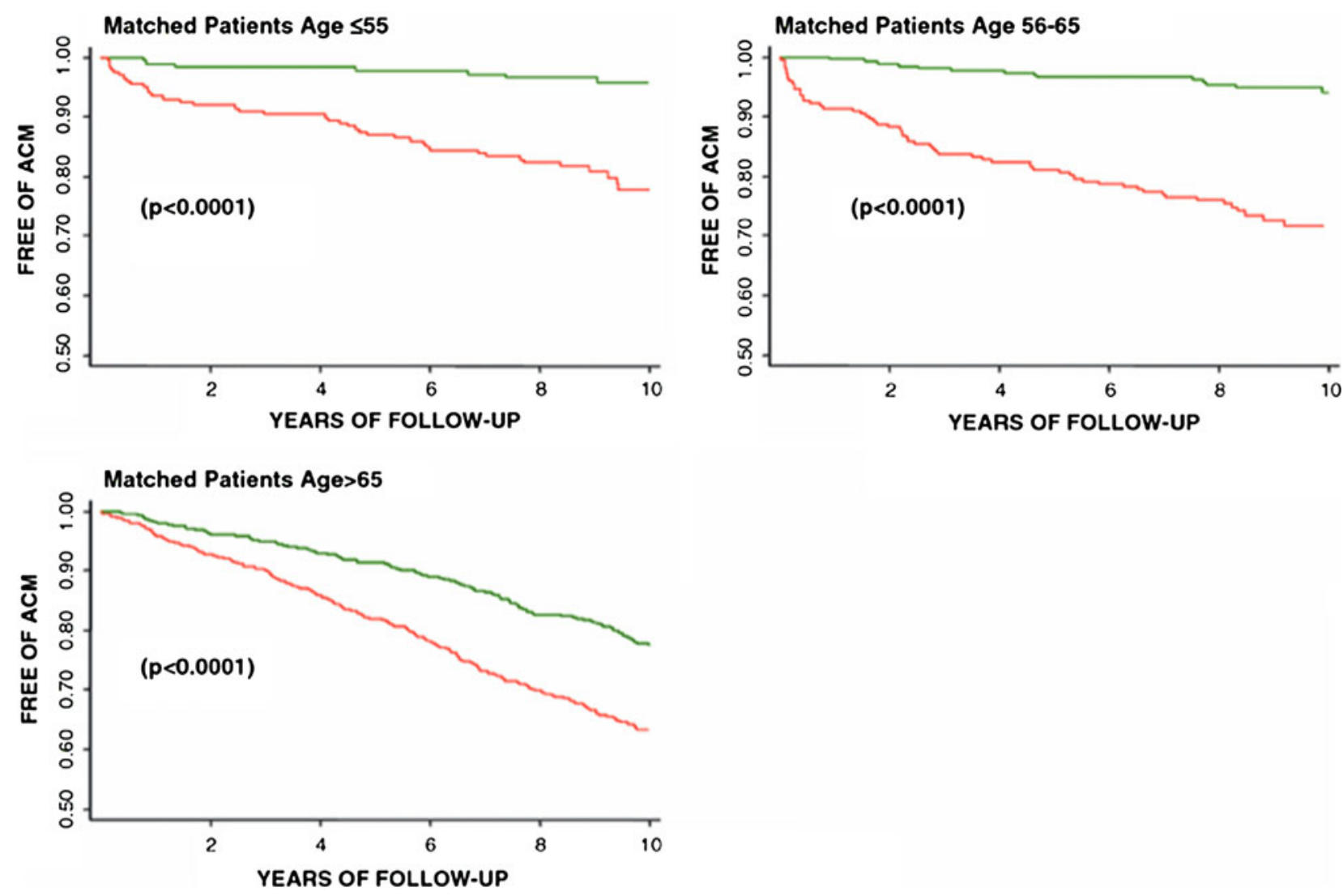

Figure 1. Comparative survival of the propensity-matched exercise and adenosine patients following division of these patients by age. Adapted from reference ${ }^{7}$.

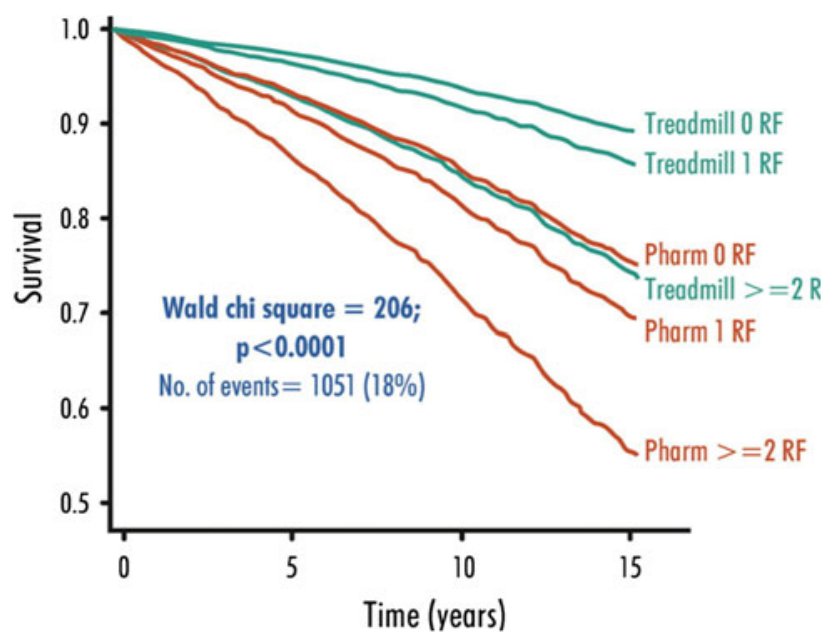

Figure 2. Adjusted Kaplan-Meier survival curves according to stress mode and CAD risk factor burden. Adjusted for age, gender, ethnicity, hyperlipidemia, family history of heart disease, body mass index, and chest pain symptoms. Adapted from reference ${ }^{8}$.

Significant predictors of outcome in the study by Ottenhoff et $\mathrm{al}^{10}$ included age, diabetes mellitus, and rate-pressure product at peak stress. However,other CAD risk factors that have been noted to be significant long-term predictors among patients with suspected $\mathrm{CAD}$, such as hypertension and smoking, were not found to be significant predictors of outcome in this study. ${ }^{5}$ In assessing this potential discordance, the 
limitations of the present study must be emphasized. First, the follow-up study reported herein represents a very small sample size. For instance, a history of congestive heart failure did not reach statistical significance as an outcome predictor in the present study, but this would have likely been a strong predictor had the present study come from a large patient sample. Second, the current report lacks important details concerning the assessment of risk factors. For instance, we are informed that $20 \%$ of patients were smokers, but we do not know what fraction of smokers were current vs former smokers. Similarly, we are not provided with any information as to how chest pain was ascertained in this study.

Nevertheless, an important finding by Ottenhoff et $\mathrm{al}^{10}$ is the substantial difference in outcomes among their patients undergoing exercise vs dobutamine-atropine SPECT-MPI patients. After one year of followup, there was a progressively greater decline in survival among their patients who underwent pharmacological stress. We are not provided information as to the comparative age and clinical profiles of the two groups, but these results parallel the results of other studies.

\section{FUTURE DIRECTIONS}

The report by Ottenhoff et $\mathrm{al}^{10}$ raises the question as to what should we demand of future studies regarding long-term outcome studies following SPECT-MPI and why? The need for future study is compelling for two reasons. First, recent observations suggest that there has been a decline in the frequency of abnormal and ischemic SPECT-MPI studies compared to that 2-3 decades ago. ${ }^{11,12}$ In one recent study, the frequency of abnormal SPECT-MPI studies fell from $40.9 \%$ to $8.7 \%$ over two decades. ${ }^{11}$ While this study was performed in patients with suspected rather than known CAD, other types of data now also point to CAD being a "milder" disease, including data indicating a decline in both the frequency ${ }^{13}$ and initial severity of myocardial infarction. ${ }^{14}$ Thus, presumably, there is now also a high frequency of non-ischemic or normal studies among patients with known or suspected CAD referred for SPECT-MPI. The high frequency of normal studies following SPECT-MPI stress testing naturally leads to increased interest in how long-term outcomes may vary according to risk factors and other clinical variables in these patients. Prospective research in this arena should include heightened standards relative to the reporting of risk-factor data, type, and severity of chest pain symptoms, results concerning functional capacity, assessment of left ventricular function (lacking in the present study), resting hemodynamic data, and other clinical factors. Since there are a considerable number of clinical variables that could potentially influence long-term outcomes among patients with known and suspected CAD, studies such as these should involve large sample sizes, perhaps necessitating the collection of pooled data from multiple centers for this purpose.

At the same time, we can expect to be increasingly challenged as to how reporting these types of data can assist in patient care. Presently, newer technologies, such as coronary calcium scanning and coronary CT angiography, are assessed not only according to how well these tests predict outcomes, but also according to whether the application of these tests favorably change outcomes. Can the impact of Nuclear Cardiology benefit by being put under the same microscope? To illustrate, with increasing data pointing to a substantially heightened risk for adverse outcomes among normal SPECTMPI patients who cannot exercise, would "emphasizedreporting" of this heightened risk lead to physicianpatient interactions that might serve to reduce this risk? Therapeutic actions that may follow the reporting of heightened long-term risk in non-ischemic patients could include, referral to programs that promote home exercise, or to programs to address musculoskeletal problems that inhibit the performance of physical activity during daily life activity. Examining such issues would certainly add considerable complexity to the study of outcomes following nuclear cardiology procedures, but could represent a model by which these very procedures could become a force for promoting primary- and secondarydisease prevention for patients in the future.

\section{References}

1. Metz LD, Beattie M, Hom R, Redberg RF, Grady D, Fleischmann $\mathrm{KE}$. The prognostic value of normal exercise myocardial perfusion imaging and exercise echocardiography: A meta-analysis. J Am Coll Cardiol 2007;49:227-37.

2. Shaw LJ, Hendel R, Borges-Neto S, Lauer MS, Alazraki N, Burnette J, et al. Prognostic value of normal exercise and adenosine $(99 \mathrm{~m})$ Tc-tetrofosmin SPECT imaging: Results from the multicenter registry of 4,728 patients. J Nucl Med 2003;44:134-9.

3. Ladenheim ML, Kotler TS, Pollock BH, Berman DS, Diamond GA. Incremental prognostic power of clinical history, exercise electrocardiography and myocardial perfusion scintigraphy in suspected coronary artery disease. Am J Cardiol 1987;59:270-7.

4. Abidov A, Hachamovitch R, Hayes SW, Friedman JD, Cohen I, Kang $\mathrm{X}$, et al. Are shades of gray prognostically useful in reporting myocardial perfusion single-photon emission computed tomography? Circ Cardiovasc Imaging 2009;2:290-8.

5. Supariwala A, Uretsky S, Singh P, Memon S, Khokhar SS, WeverPinzon O, et al. Synergistic effect of coronary artery disease risk factors on long-term survival in patients with normal exercise SPECT studies. J Nucl Cardiol 2011;18:207-14 quiz 217.

6. Navare SM, Mather JF, Shaw LJ, Fowler MS, Heller GV. Comparison of risk stratification with pharmacologic and exercise stress myocardial perfusion imaging: A meta-analysis. J Nucl Cardiol 2004;11:551-61. 
7. Rozanski A, Gransar H, Hayes SW, Friedman JD, Hachamovitch $\mathrm{R}$, Berman DS. Comparison of long-term mortality risk following normal exercise vs adenosine myocardial perfusion SPECT. J Nucl Cardiol 2010;17:999-1008.

8. Supariwala A, Uretsky S, Depuey EG, Thotakura G, Kanneganti S, Guriginjakunta $\mathrm{N}$, et al. Influence of mode of stress and coronary risk factor burden upon long-term mortality following normal stress myocardial perfusion single-photon emission computed tomographic imaging. Am J Cardiol 2013;111:846-50.

9. Hachamovitch R, Hayes S, Friedman JD, Cohen I, Shaw LJ, Germano G, et al. Determinants of risk and its temporal variation in patients with normal stress myocardial perfusion scans: What is the warranty period of a normal scan? J Am Coll Cardiol 2003;41:1329-40.

10. Ottenhoff MJM, Wai MCGTJ, Boiten HJ, Korbee RS, Valkema R, van Domburg RT, et al. 12-year outcome after normal myocardial perfusion SPECT in patients with known coronary artery disease. $\mathrm{J}$ Nucl Cardiol 2013. doi:10.1007/s12350-013-9713-3.

11. Rozanski A, Gransar H, Hayes SW, Min J, Friedman JD, Thomson LE, et al. Temporal trends in the frequency of inducible myocardial ischemia during cardiac stress testing: 1991 to 2009. J Am Coll Cardiol 2013;61:1054-65.

12. Iskandrian $\mathrm{AE}$, Hage FG. Declining frequency of ischemia detection using stress myocardial perfusion imaging. J Am Coll Cardiol 2013;61:1066-8.

13. Yeh RW, Sidney S, Chandra M, Sorel M, Selby JV, Go AS. Population trends in the incidence and outcomes of acute myocardial infarction. N Engl J Med 2010;362:2155-65.

14. Myerson M, Coady S, Taylor H, Rosamond WD, Goff DC Jr, Investigators A. Declining severity of myocardial infarction from 1987 to 2002: The atherosclerosis risk in communities (ARIC) study. Circulation 2009;119:503-14. 